\title{
After 150 years of research, fatigue still causes $85 \%$ of failures
}

\author{
J. Volak ${ }^{1} \&$ V. Mentl ${ }^{2}$ \\ ${ }^{1}$ Research and Testing Institute Ltd., Pilsen, Czech Republic \\ ${ }^{2}$ University of West Bohemia, Pilsen, Czech Republic
}

\begin{abstract}
The fatigue phenomenon is said to be responsible for more than $80 \%$ of structural failures and operational accidents. One of the most important branches of industry, where unexpected outages can cause extremely expensive costs is the power producing industry. The steam turbine rotors represent large, expensive and, in the case of failure, potentially dangerous components. Their local properties generally differ from one forging to another, or if we compare head and bottom parts of the original ingot, or central and circumferential locations of one rotor body respectively, or if we compare the properties of separate discs, e.g. in the case of welded rotors. These differences stem from both even slight changes in the chemical composition (of separate heats or even within one ingot), heat treatment and in the differences in technology with respect to the real shape and size of the forgings in question.

At present, questions on quantitative evaluation of remaining lifetime (to avoid failure) become urgent and, because fatigue is the most frequent cause of material degradation and resulting structural components failures, the remaining lifetime assessment is based on the evaluation of mechanical properties before and after some time of service. The original material data are usually tested by means of classic test specimens, which can hardly be used in the case of components in service, where there is no possibility to withdraw a sufficient volume of representative material for the manufacturing of a classic test specimen. In such cases today, methods of semi-destructive removal of a small volume of test material are utilized. This makes it possible to produce miniature test specimens.

This paper describes the results of fatigue tests performed on miniature test specimens in comparison with the classic fatigue tests for several alloys applied
\end{abstract}


in the power producing industry. The miniature test specimens were produced by water-jet cutting from the large test specimens. With respect to the specimen shape, stress concentration had to be taken into consideration for the purposes of comparison with the classic test specimens.

Keywords: fatigue, failure risk assessment, remaining lifetime evaluation.

\section{Introduction}

Fatigue is still the prevailing cause of failure of metallic, plastic and ceramic components. In cases of cyclic loading of test specimens or structural components, the cumulation of cyclic plastic deformation causes failure below ultimate strength and even yield point values.

At present, reliable quantitative evaluation of remaining lifetime becomes urgent and because fatigue is the most frequent cause of material degradation and resulting structural components failures, the most important means of remaining lifetime assessment is the evaluation of fatigue properties before and after some time of service. The original material data are usually tested by means of traditional (standardized) test specimens, which can be hardly used in case of components in service, where there is no possibility to withdraw sufficient volume of representative material for the traditional test specimen manufacturing and testing. In such cases today, new untraditional methods of semi-destructive removal of a small volume of test material by grinding or an electro-discharge method are utilized. This makes it possible to produce a miniature test specimens. The direct comparison of the results must be then based on reliable correlation between traditional and miniature test specimen results.

The basic mechanical characteristics of fatigue behaviour of structural materials are:

a) Woehler $(\mathrm{S}-\mathrm{N})$ curve describing the relationship between the amplitude of loading and the resulting number of cycles to failure,

b) Manson-Coffin $(\varepsilon-N)$ curve describing the relationship between the amplitude of deformation and the resulting number of cycles to failure,

c) Paris-Erdogan law describing the relationship between the crack growth rate and the stress intensity factor.

All the three abovementioned material characteristics are used in engineering practice. The Woehler ( $\mathrm{S}-\mathrm{N})$ and Manson-Coffin curves treat the material as a mechanical continuum and include all the stages of the fatigue process, the Paris-Erdogan equation describes the macroscopic crack growth only.

It is well known that the specimen size has a negligible effect in the case of uniaxial tensile loading, and thus the yield point and ultimate strength values are not dependent on the cross section size. On the other hand, the failure process during fatigue loading depends on the specimen or component size, i.e. the increasing specimen size has a negative effect on the specimen life. This fact is caused primarily by the stress gradient in the respective cross section, e.g. at bending loading, or due to stress concentrators, or due to the simple fact that it is not possible to produce real components free of defects. 
At present, questions on quantitative evaluation of remaining lifetime become urgent and the most important means of remaining lifetime assessment is the evaluation of fatigue properties before and after some time of service.

Prediction of total service life of cyclically loaded structural components or their remaining lifetime evaluation after some time of service represent important problem both in components, structures and machines design and exploitation.

Theoretically, the fatigue life can be divided into four stages:

1. Changes of mechanical properties at the beginning of fatigue loading resulting in saturation of hysteresis loops.

2. Initiation of numerous crystallographic microcracks mostly on the component surface.

3. Stage of macrocrack propagation.

4. Fracture.

In practical situations often, the loaded component contains imperfections of various kind and origin, structural and technological notches, geometrical discontinuites, etc. and total fatigue life of a component in service thus may be approximated by the third stage only, i.e. macrocrack propagation described by the Paris-Erdogan Law. And, whereas the macroscopic cracks can be observed by numerous experimental techniques, the material degradation is not clearly visible. Some NDT methods nevertheless exist, e.g. X-Ray diffraction [3-5].

There are several problems related to the material properties degradation assessment during service:

1. The material of a component is not homogenous (as a result of applied technology) as far as its chemical composition and structure is concerned. As a suitable example, large castings and forgings are this case.

2. Components are of complex geometry, contain geometry discontinuities, notches, etc., so that even at simple (e.g. uniaxial) loading and uniform temperature field, individual localities of the component can reveal different degree of material properties degradation.

3. Original (virgin) mechanical properties are not known from various reasons. The problem is complicated also by point 1 . These data should be then stored during the whole service life of the component.

4. During component operation it is not possible to withdraw sufficient volume of material from the component, because the classic test specimens used acc. to existing standards for the mechanical properties measurement are mostly too large.

5. Alternative ways of mechanical properties measurement have to be used based e.g. on the use of miniature test samples or semidestructive test methods. The results of such tests must then be correlated to the classic ones and these correlations must be based on the abovementioned items.

Thus the goal of the presented research was to establish correlation(s) of fatigue test results between classic and miniature test specimens. 


\section{Method of material sampling of real components}

For the purposes of material properties evaluation in case of components in service, a small volume of material can be withdrawn by means of special device (see Fig. 1).

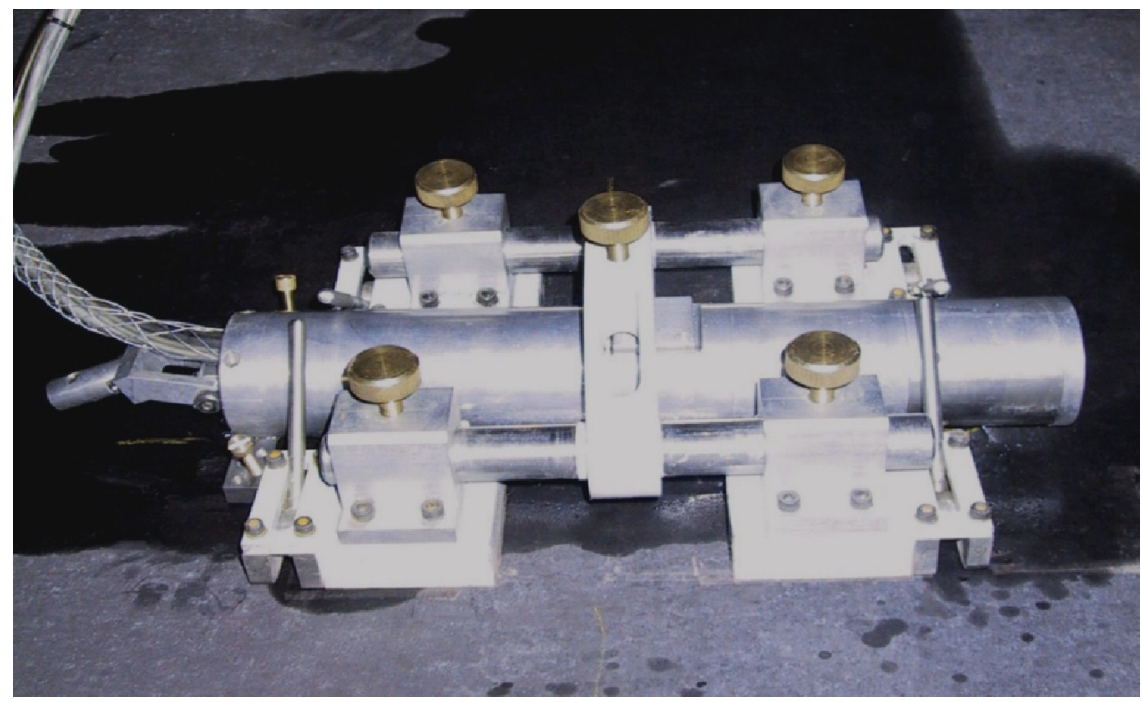

Figure 1: $\quad$ Test material sampling from outer surface sampling machine [6].

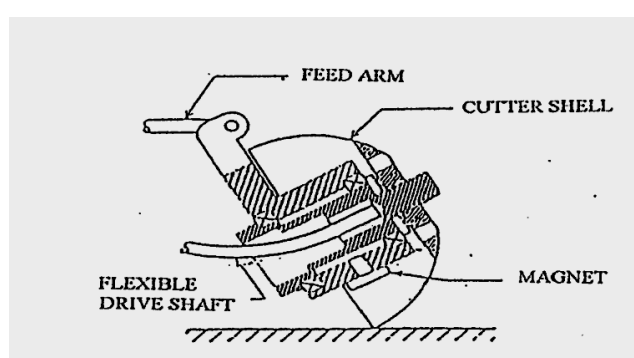

(a)

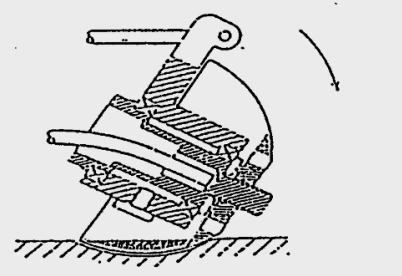

(b)

Figure 2: The principle of the sampling by SSamTM-2 sampling machine [6].

The principle is shown in Fig. 2. The resulting surface damage after the material removal is relatively small and in many cases it can be neglected causing no substantial stress concentration or wall thickness reduction. For example, shallow cracks discovered during in-service inspections in steam boiler tubing are also frequently removed by grinding. The process of material sample removal is slow and takes place at intensive cooling, so that material properties are not affected. An example of the location of material removal is then seen in Fig. 3. 


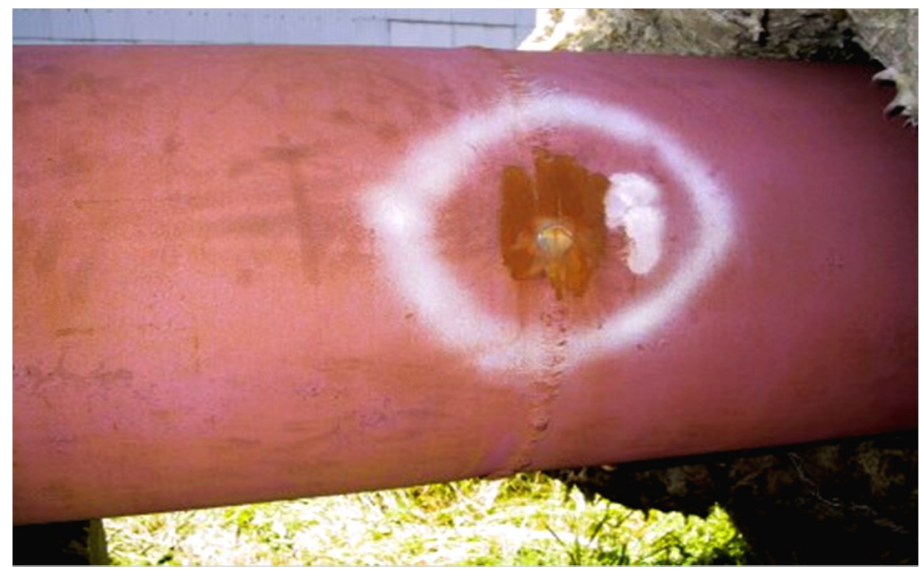

Figure 3: $\quad$ An example of test sampling location [7].

The piece of material removed from the component (see Fig. 4) can be used for chemical and microscopic investigation and also for the purposes of the mechanical testing, e.g. for the determination of yield point and ultimate strength values, creep properties at elevated temperatures, transition temperatures, fracture toughness, and also the fatigue properties. All the abovementioned values are nevertheless measured by means of non-standardized test specimens and thus the obtained results must be correlated with the classic ones.

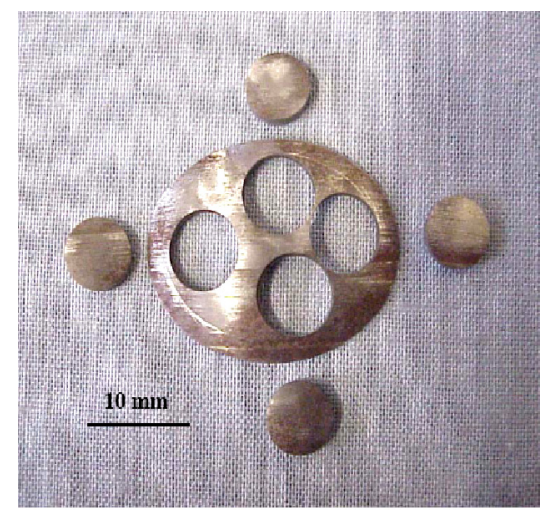

Figure 4: A sample of removed material [6].

The necessary correlations between classic and miniature characteristics must be known prior to remaining lifetime evaluation and can be determined in laboratory without material removal from real components. The test specimens can be produced by mechanical manufacturing or water jet cutting (see Fig. 6). 

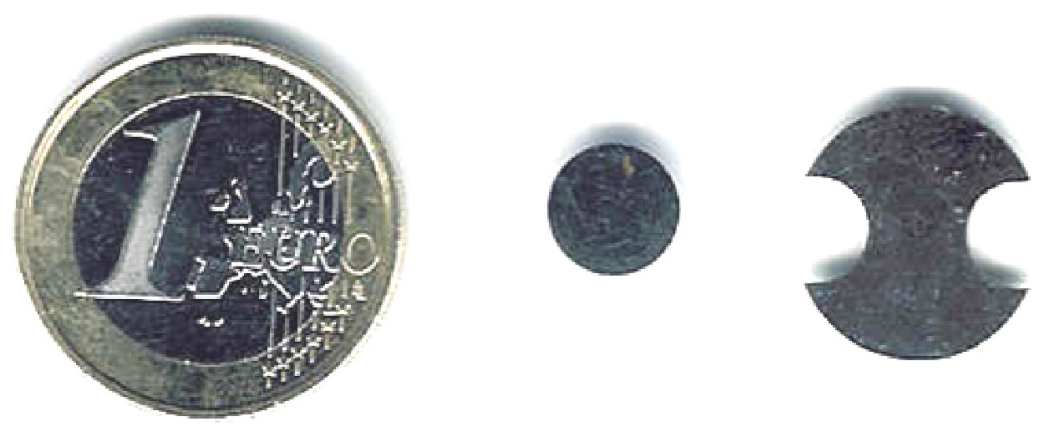

Figure 5: $\quad$ Miniature specimens for small punch and fatigue tests.

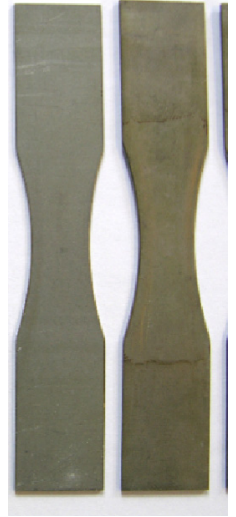

Figure 6: Classic fatigue test specimens.

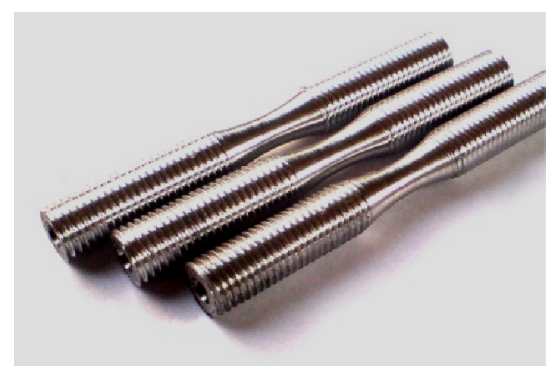

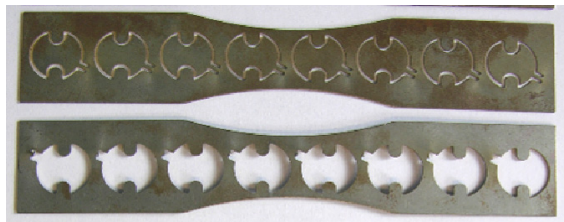

Figure 7: Miniature fatigue test specimens.

The geometry of the miniature test specimens used for the fatigue test causes stress concentration within the cross section and it must be taken into consideration when assessing and correlating the test results. The performed FEM analysis revealed that the stress concentration factor in case of the miniature test specimens used here is $\mathrm{k}=1.33$ (see Fig. 8). 


\section{Experimental procedure}

Several steels and Al-alloys were fatigue tested at room temperature for the purposes of correlation determination between classic and miniature test specimens test results. (Because of the commercial origin, the details of the tested materials are not stated here.)
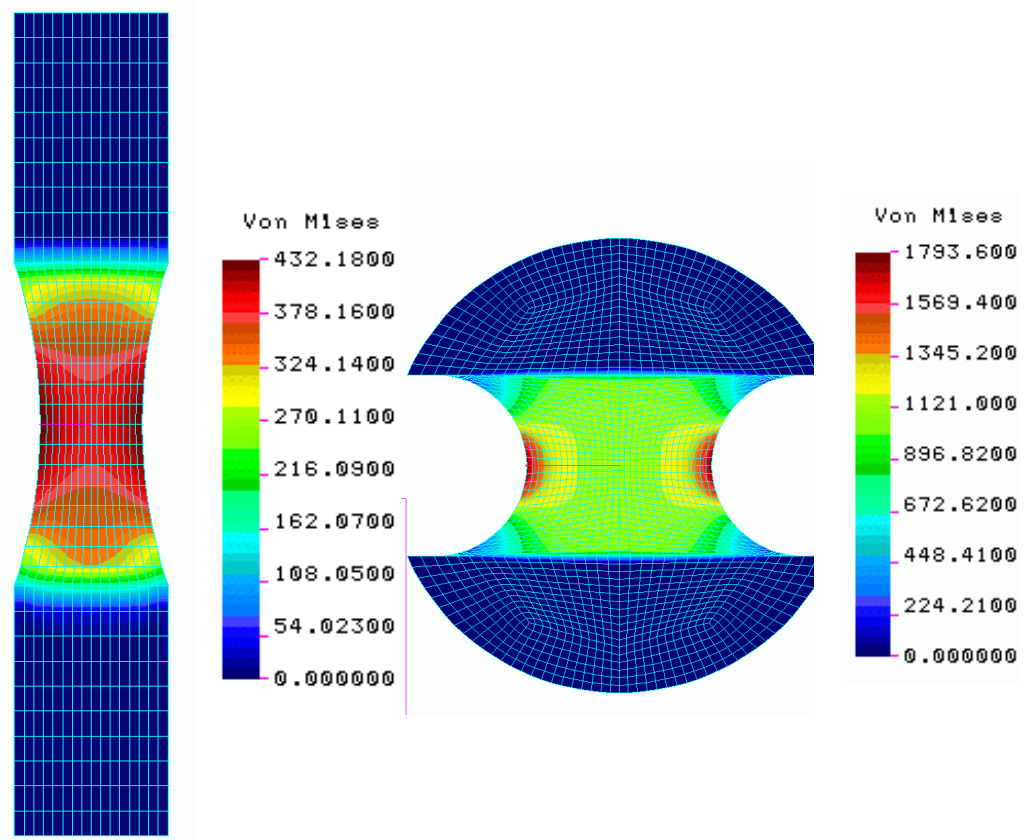

Figure 8: $\quad$ Stress concentration determined by FEM model.

In the diagrams in Figures 9-12, the "classic fatigue" represents the data obtained by means of traditional standardized test specimens. The "nominal stress" represents the data obtained on miniature test specimens, where no stress concentration was taken into consideration, and "stress concentration" represents the data obtained on miniature test specimens, where the stress concentration factor (determined by FEM) of $\mathrm{k}=1.33$ was taken into consideration.

\section{Conclusion}

It is well visible from the experimental results, that the S-N (Woehler) curves of miniature test specimens have a different (steeper) course in comparison with the traditional ones for all the tested materials. At present, no unique generally valid correlation between the classic and miniature test specimen results has been found. 
S-N Curve at RT

Steel sheet, designation $\mathrm{X} 3$

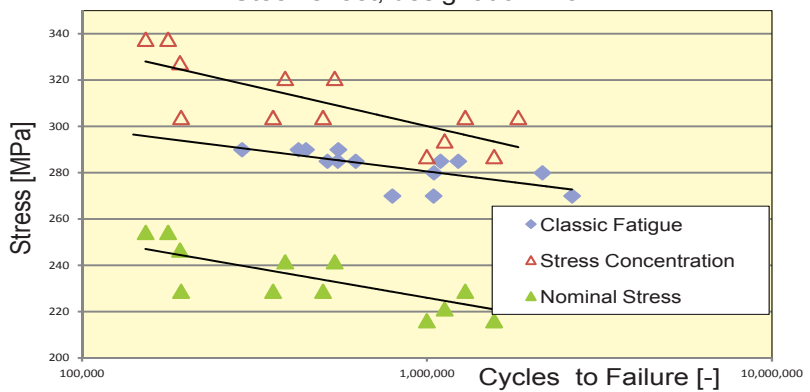

Figure 9: $\quad$ S-N (Woehler) curves, steel "X3".

S-N Curve at RT

Steel Sheet, designation $\mathrm{X} 6$

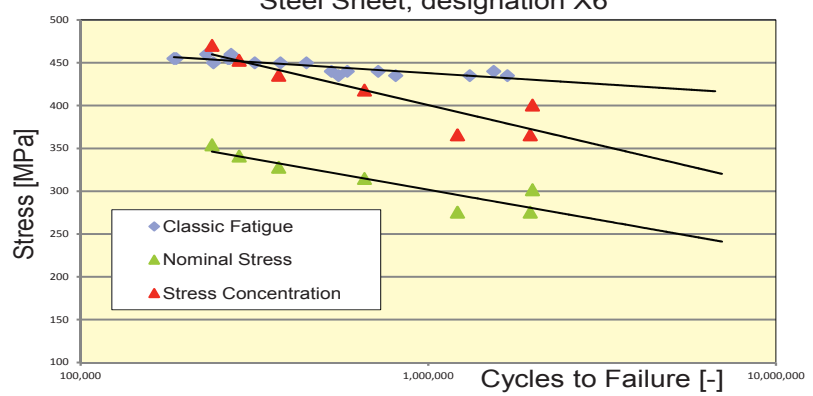

Figure 10: S-N (Woehler) curves, steel "X6".

S-N Curve at RT

Steel sheet, designation $\mathrm{X} 7$

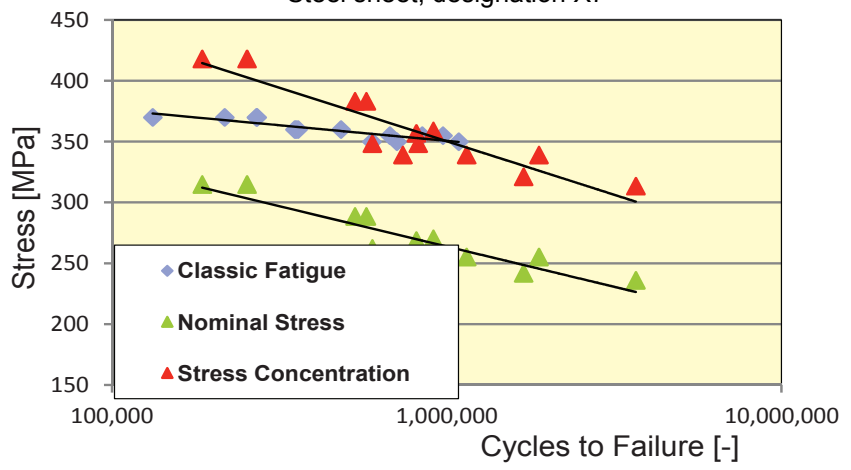

Figure 11: S-N (Woehler) curves, steel "X7". 


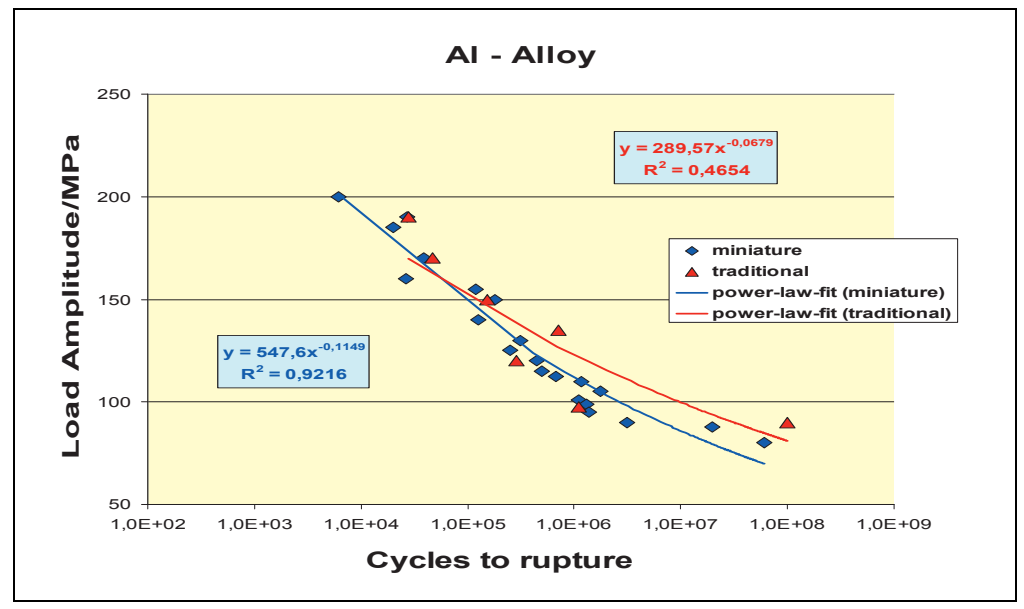

Figure 12: $\quad$ S-N (Woehler) curves, Al-alloy.

Thus, the recommended solution (steps) for the failure prevention and the remaining lifetime evaluation might be as follows:

1. To establish correlation between classic and miniature test results prior to service in the situation when the material is in "virgin" state and no service material properties degradation exists.

2. This correlation must, in case of large components, e.g. steam turbine rotors, be established in the locations, where the test samples will be in future removed for the purposes of material degradation assessment. The material mechanical properties can differ substantially within the forging.

3. The relevant data must be stored for the purposes of future comparison with the data measured after certain service period. In this situation, miniature test specimens can be used only and the previously established correlation should be used. (The assumption that the correlation between classic and miniature test specimens is the same both for virgin and degraded material should be proved.)

4. It is recommended to make out a "birth-certificate" of the component, where all the relevant data are summarized and, during service inspections and performed investigation, recorded and stored.

Such a procedure is based on real experimental data in opposite to the remaining lifetime assessment methods based on many (often risky) assumptions or the permanent storing of numerous variables data on pressure, temperatures, water quality etc. (e.g. in case of steam turbine boilers) for many years and their evaluation by methods based on theories, which in the time of the remaining 
lifetime evaluation are already 20,30 or even more years old and maybe surmounted.

The necessary costs for the abovementioned procedure will be balanced by lowering the risk of an unexpected failure and inevitably related economic losses and more precise evaluation of remaining component or structure lifetime, what makes it possible to assess the risk of prolonged operation, to plan and minimize structure outages and make use of the closed loop information with respect to the future production and maintenance.

\section{Acknowledgements}

The research was supported by Czech Ministry of Industry and Commerce, project No. FR-TI4/602.

\section{References}

[1] Mentl V.: Mapping of Fracture Toughness Values in Large Forgings, Proc. ECF 18, Dresden, Germany, 2010, ISBN 978-3-00-031802-3.

[2] Volak J., Mentl V.: A Comparison of Fatigue Characteristics of Structural Steels Measured by means of Classic and Miniature Test Samples, Proc. ICMFF9, Parma, Italy, 6/2010, ISBN 978-88-95940-31-1.

[3] Fiala J., Mentl V.: Degradation Assessment of Fatigue by X-Ray Diffraction Technique, Int. Conf. Fatigue Design 2007, Senlis, France, 2007.

[4] Fiala J., Mentl V.: Degradation Assessment of Welded Joints by X-Ray Diffraction Technique, Int. Conf. “WELD”, Geesthacht, Germany, 2005.

[5] Kolarik V. et al. An Innovative Lifetime Monitoring and Improving Method for High Temperature Components: Xpection, Int. Conf. "Plant Life Extension", Cambridge, UK, 2004.

[6] Small punch test method for metallic materials, CEN Workshop Agreement, CWA 15627, 2007.

[7] Kubon, Z.: Small sampling test method, Vítkovice-Research and Development, Ltd., 2005. 